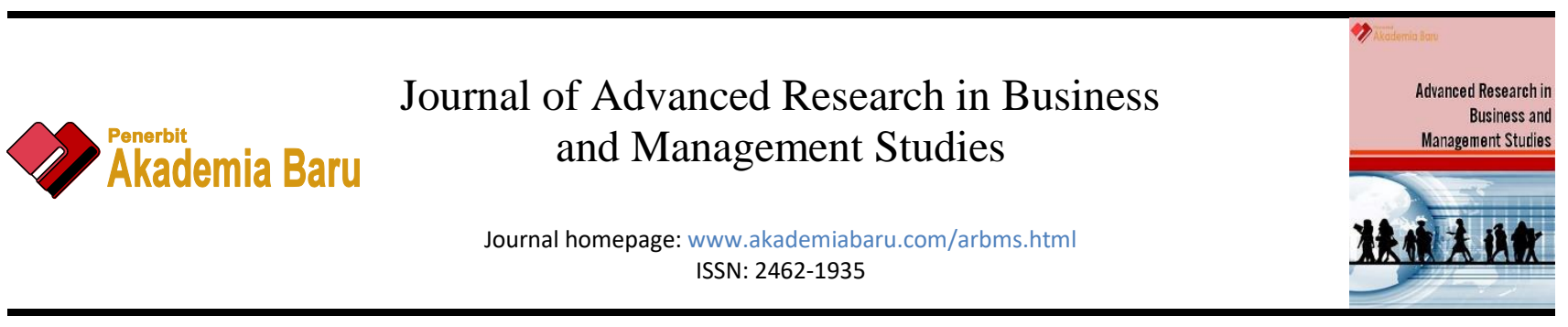

\title{
Factors Determine the Behavioural Intention in Adopting the Blockchain Technology by Malaysian Public Sector Officers
}

\author{
Mohd Izzat Latif ${ }^{1}$, Zukarnain Zakaria1,* \\ 1 Malaysia - Japan International Institute of Technology (MJIIT), University Teknologi Malaysia, Jalan Sultan Yahya Petra,54100 Kuala Lumpur, \\ Malaysia
}

\section{ABSTRACT}

Recently, Blockchain technology has attracted great attention in both private organisations and the public sector around the world. However, not many are aware and understand this new technology. Thus, lack of understanding of the Blockchain technology could influence the intention in adopting the technology. Therefore, the objective of this paper is to identify the behaviour intention towards adopting Blockchain Technology in the Malaysian Public Sector. Data were gathered using a questionnaire to analyse the relationship between factors such as Performance Expectancy, Effort Expectancy, Social Influence, Facilitating Conditions and Trust with Behavioural Intention to adopt Blockchain Technology. The data were gathered from 100 officers in various government department. The survey revealed that majority of the government officers are aware about the Blockchain technology. However, most of them have inadequate exposure and knowledge about the technology. Findings from the regression analysis found that Trust, Performance Expectancy and Social Influence positively and significantly influence the behaviour intention of government officers in adopting Blockchain technology. Meanwhile, Effort Expectancy and Facilitating Conditions were found not significant. The findings from this study suggest that it is essential to develop strategies to implement a suitable Blockchain application in the public sector. Prior to such implementation, it is imperative for government officers to be equipped with knowledge, skills and resources related to the Blockchain technology.

Keywords:

Blockchain Technology, Public Sector,

UTAUT, Behavioural Intention, Malaysia

Copyright $@ 2020$ PENERBIT AKADEMIA BARU - All rights reserved

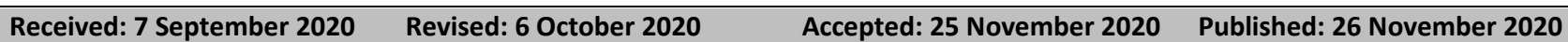

\section{Introduction}

In recent years, Blockchain Technology has been a popular topic that has attracted attention of many industry players as well as academician. Subsequently, Blockchain has received increasing interest in the literature. Many considered Blockchain as innovative and transformative technology that has a great potential to change the way the world works, especially in the government sector. However, since Blockchain is relatively new technology, the knowledge about the technology is still very limited, especially with regards to what, where and how the technology can be effectively implemented [21].

\footnotetext{
* Corresponding author.

E-mail address:m-zukar@utm.my
}

https://doi.org/10.37934/arbms.20.1.3443 
Government agencies all over the world have started exploring the potential and the benefits of implementing Blockchain systems in their organisations [5]. In Malaysia, for instance, MIMOS Berhad [20] stated that the Malaysian Ministry of Science, Technology and Innovation (MOSTI) is seriously looking at the Blockchain technology. This is to ensure that Malaysia is not left behind in this technology advancement. The Malaysian Industry-Government Group for High Technology (MIGHT) highlighted that Malaysia would be adopting the Blockchain technology by the year 2025. As of now, the Blockchain technology in Malaysia is still in its emerging stage due to lack of understanding and awareness on the technology. The lack of comprehension could hamper the implementation and usage of Blockchain technology.

Batubara et al. [5] highlighted that countries such as China, Estonia, the Netherlands, the United Arab Emirates, the United Kingdom and Sweden are actively promoting the usage of Blockchain technology in their public sectors. T, they argued that the main reason of adopting Blockchain technology in the public sector is related to trust and transparency issue; as government activities are susceptible to fraud, corruption and lack of trust between and within the agencies. With respect to this, the Blockchain technology has several features that make it ideal for the public sector especially in dealing with matters that related to trust, traceability, transparency, and security. In other words, the Blockchain system is capable to help government sector to deal with the issues such as corruption, bureaucracy and accountability.

Lack of awareness and understanding towards the Blockchain technology could limit the potential usage of Blockchain technology in the public sector. On top of this, the introduction of new technology requires a full support and commitment from the staff in the organisation in order to be successful. With respect to this, the introduction of new technology system such as Blockchain can be unfavourable to the staff, thus creating resistance in adopting the technology among the staff. Therefore, the main objective of this paper is to identify the potential factors that may influence the adoption of Blockchain technology in the Malaysian public sector. Specifically, this paper investigates the government officers' perception towards Blockchain technology to attain performance in job efficiency, ease of using the technology, and the ability of an organisation and its technical infrastructure to support the technology.

\section{Literature Review}

Several theoretical models have been developed to explain about the users' adoption towards new technologies. For instance, there were models that demonstrate how information technology systems are accepted and used [2,7]. For this, among the most commonly used theories are the Theory of Planned Behaviour (TPB) [1,2], the Technology Acceptance Model (TAM) [6-8], the Diffusion of Innovation (DOI) [22], and the unified theory of acceptance and use of technology (UTAUT) [27].

UTAUT was developed by Venkatesh, Morris, Davis and Davis [27] is a unified model that elucidate consumer adoption towards new technology. This model has been widely used as a fundamental model on the studies related to organisational technologies [16]. According to this model, there are five factors that can influence the behavioural intention towards a new technology; performance expectancy (PE), effort expectancy (EE), social influence (SI), facilitating condition (FC) and trust (TR). The conceptual framework of this study that has been derived base on the UTAUT as shown in Figure 1. 


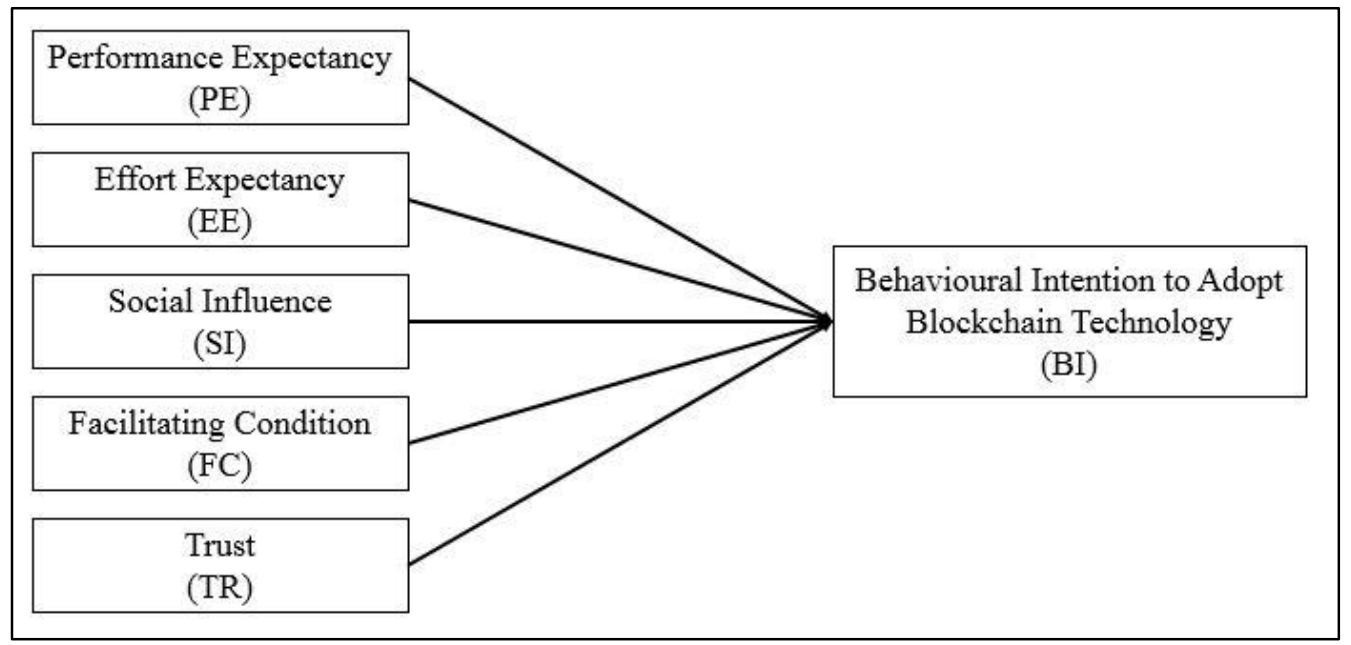

Fig. 1. Conceptual Framework of the study

Behavioural Intention (BI) can be defined as the degree of intention of the users to carry out certain action, which also indicate user behaviour in voluntarily manner [11]. Specifically, behavioural intention measures a person's inclination to engage in a specific behaviour [27], and this variable has been used as an indicator for actual behaviour among users in technology. It has also been reported that behavioural intention is one of the key determinants of technology usage among individuals [17].

Meanwhile, Performance Expectancy (PE) is referring to the degree of which users gain benefits in using a technology while carrying out their activities [28]. For example, Sun, Cao and You [24] in their study reported that perceived usefulness is positively influence the behavioural intention toward the usage of mobile-commerce. A study by Leong et al. [15] that using the structural equation modelling (SEM) approach also found the same result in the case of mobile-credit card. The findings from these empirical studies revealed that performance expectancy is a factor that influence individual behavioural intention to adopt a technology.

Effort Expectancy (EE) is measuring the level of a technology ease of use [12]. For instance, Tan, Sim, Ooi and Phusavat [25] in their study found that perceived ease of use of the technology significantly influences the adopting of mobile-learning. In contrast, Wu, Tao and Yang [29] proved that effort expectancy does not significantly influence the behavioural intention of consumers to adopt $3 \mathrm{G}$ mobile telecommunication services in Taiwan.

Venkatesh et al. [27] define Social influence (SI) as the degree that other people will influence someone to use a new technology. In other words, social influence is an individual's perception that others believe the individual should adopt the technology. For example, Akour [3] in his study found that extrinsic influence (superior and peer influence) is the most influential factor towards online learning acceptance in tertiary education.

Facilitating Condition (FC) is the perception that organisational and technical infrastructures exist to support the use of technology [27]. Using multiple linear regressions, Yeoh and Chan [30] in their study found that facilitating condition significantly influences the behavioural intention to adopt internet banking in Malaysia. Similarly, Wu et al. [29] found that facilitating condition significantly influences behavioural intention for adopting $3 \mathrm{G}$ mobile telecommunication services. The findings from these empirical studies clearly indicated that facilitating condition is a significant factor in influencing the behavioural intention to adopt a new technology.

Trust refers to a readiness of a party to tolerate another party's actions on the premise that the other party may carry out a specific activity that is essential to it [19]. One aspect that influences trust is the characteristics of the trustee. The tendency to trust differs among people with according to 
their experience, personality and cultural backgrounds. Trust is articulated as a deterrent to technology acceptance by various social science researchers [14].

\section{Research Methodology}

This paper empirically examined the Behavioural Intention (BI) of Malaysian public sector officials towards Blockchain technology by using the UTAUT model as a basis. In the model BI is depends on five factors, which is Performance Expectancy (PE), Effort Expectancy (EE), Social Influence (SI), Facilitating Conditions (FC) and Trust (TR). The data for this study were gathered using structured questionnaires of closed-ended questions that distributed through Goggle form and email.

The data collection instrument used in this study is divided into seven main sections. The first section, which is the demographic profiles section consists the questions that focusing on collecting information about respondent background such as gender, age, educational level, position level, and years of experience in service. In addition, this section also consists questions with regard to the respondent's awareness, exposure and experience in using Blockchain Technology. The remaining sections of the questionnaire are focusing on the six variables studied, which is the behavioural intention (BI) and the five respective factors. In total, there were 30 questions were included in the questionnaire that focusing on these six variables. Specifically, each of the variables is measured by five items of 5-points Likert scale.

The invitations to participate in the survey were sent through email and WhatsApp application to a total of 386 government officers in various departments and ministries in Malaysia. The targeted respondents were officers that hold management position dealing with information technology planning and development in the respective government departments and ministries. In this study, a non-probability purposive sampling methods were used in selecting the samples to ensure that the background of the respondent is fit with the objective of this study, which is to evaluate the behavioural intention towards adopting Blockchain among government officers that dealing with the technology planning in their organisation.

Out of 386 officers that were invited to participate in the survey, 100 of them have answered the questionnaire through the Google Forms. The number of respondents are considered as sufficient following the rule of thumb, which should be greater than 30 and less than 500 for most types of research [23]. The collected data was analysed descriptively, and statistically using correlation and regression analysis by IBM SPSS Version 23.

At the initial stage in the data analysing process, the Cronbach's alpha was calculated. The purpose is to test the internal consistency of the items used in measuring the constructs of the study. In interpreting the Cronbach alpha, the value of the Cronbach's alpha that below 0.70 indicates the reliability of the data is disputed [26]. Meanwhile, the Cronbach's alpha coefficient value approaching 1.0 , suggesting the better internal consistency between the items used in measuring the construct. Table 1 presents the result from the reliability tests. The results showed that the Cronbach alpha values for all relevant constructs in this study are more than 0.9. Based on these statistics, this paper concluded that the items used in measuring the respective construct are internally consistent, hence reliable. 


\section{Table 1}

Results of Cronbach's Alpha statistics for internal consistency tests

\begin{tabular}{lcc}
\hline Factors of the Proposed Research Model & Cronbach's Alpha & No. of Items \\
\hline Behavioural Intention (BI) & .963 & 5 \\
\hline Performance Expectancy (PE) & .958 & 5 \\
\hline Effort Expectancy (EE) & .933 & 5 \\
\hline Social Influence (SI) & .921 & 5 \\
\hline Facilitating Conditions (FC) & .914 & 5 \\
\hline Trust (TR) & .947 & 5 \\
\hline Cronbach's Alpha for overall model & .971 & 30 \\
\hline
\end{tabular}

\section{Results}

\subsection{Demographic Profile}

The discussion of this section begins by describing the demographic background of the respondents that participated in the survey. Table 2 presents the descriptive statistics on the selected demographic factors of the respondents. Statistics in Table 2 show that out of 100 respondents, 52\% are male and $48 \%$ are female. The statistics clearly showed the distribution of the respondents by gender is almost balance. Meanwhile, for age distribution, the result from the survey showed that majority of respondents (71\%) are between 31 to 40 years old, while $3 \%$ are between 51 to 60 years. Only $1 \%$ of the respondents are aged below 30 years old.

With regard to the respondents' academic qualification, the result from survey showed that the majority of them (56\%) have a bachelor's degree or equivalent. This is because a minimum academic qualification to hold a management position in the Malaysian public sector is a Bachelor's degree. However, recently, number of government officers that possess a postgraduate degree such as Masters and $\mathrm{PhD}$ are in increasing trend. This trend can also clearly be observed in this study, where about $38 \%$ of the respondents in this study are a Master's degree holder, and $6 \%$ have a $\mathrm{PhD} /$ Doctorate degree.

The majority (55\%) of the respondents are junior officers (grade $41 / 44$ ), while $37 \%$ are in a middle management position (grade 48/52), and only $8 \%$ are holding a senior management position (grade 54 and above). As it is can be seen from Table 2, majority (49\%) of the respondents have served the public sector for 11 to 15 years, while $7 \%$ of them already served the public sector for more than 20 years. In terms of the working experience, most officers have worked beyond 5 years. Based on the respondents' background that has been discussed above, this paper concluded that the respondents of this study are possess sufficient experience in government management and policy. In the other words, the respondents of this study have enough knowledge, experience and qualification to provide the necessary information needed by this study.

Respondent has also been asked about their awareness and experience towards Blockchain technology. With regard to their awareness towards the technology, the survey found that about $63 \%$ of the respondents are aware about the existence of Blockchain technology, and $37 \%$ stated that they are not aware about the technology. However, a majority of the respondents (86\%) answered that they never been exposed to the technology. Only $14 \%$ of the respondents claimed that they have been exposed to Blockchain technology. Similarly, only $15 \%$ of the respondents reported that they have experience of using the Blockchain technology. The majority of respondents (85\%) stated that they still do not have any experience regarding this technology. 


\section{Table 2}

Summary of respondent demographic profiles

\begin{tabular}{|c|c|c|}
\hline Demographic Profile & Frequency & Percentage \\
\hline \multicolumn{3}{|l|}{ 1. Gender } \\
\hline Male & 52 & $52 \%$ \\
\hline Female & 48 & $48 \%$ \\
\hline \multicolumn{3}{|l|}{ 2. Age group } \\
\hline 21 to 30 years old & 1 & $1 \%$ \\
\hline 31 to 40 years old & 71 & $71 \%$ \\
\hline 41 to 50 years old & 25 & $25 \%$ \\
\hline 51 to 60 years old & 3 & $3 \%$ \\
\hline \multicolumn{3}{|l|}{ 3. Education Level } \\
\hline Degree & 56 & $56 \%$ \\
\hline Masters & 38 & $38 \%$ \\
\hline PhD / Doctorate & 6 & $6 \%$ \\
\hline \multicolumn{3}{|l|}{ 4. Position Level } \\
\hline Junior Management (41/44) & 55 & $55 \%$ \\
\hline Middle Management (48/52) & 37 & $37 \%$ \\
\hline Senior Management (54 and Above) & 8 & $8 \%$ \\
\hline \multicolumn{3}{|l|}{ 5. Years in service (experience) } \\
\hline 1 to 5 years & 4 & $4 \%$ \\
\hline 6 to 10 years & 29 & $29 \%$ \\
\hline 11 to 15 years & 49 & $49 \%$ \\
\hline 16 to 20 years & 11 & $11 \%$ \\
\hline More than 20 years & 7 & $7 \%$ \\
\hline \multicolumn{3}{|c|}{ 6. Are you aware of Blockchain Technology? } \\
\hline Yes & 63 & $63 \%$ \\
\hline No & 37 & $37 \%$ \\
\hline \multicolumn{3}{|c|}{ 7. Have you had any exposure (training etc.) to Blockchain Technology? } \\
\hline Yes & 14 & $14 \%$ \\
\hline No & 86 & $86 \%$ \\
\hline \multicolumn{3}{|c|}{ 8. Do you have any experience using Blockchain Technology? } \\
\hline Yes & 15 & $15 \%$ \\
\hline No & 85 & $85 \%$ \\
\hline
\end{tabular}

\subsection{Behaviour Intention and Demographic Factors}

The next step in the data analysis procedures of this study is performing the inferential analysis. The analysis starts by comparing the behaviour intention in adopting Blockchain technology between the groups in the demographic factors studied. The purpose of this analysis is to determine whether there is a significant difference in the level of behaviour intention towards adopting Blockchain technology among groups within the demographic factor of the Malaysian government officers. Table 3 presents the results from the one-way ANOVA tests. The results show that the behaviour intention of adopting Blockchain Technology between group in gender, age, education level, position level and years in service are not significant at $5 \%$ levels. The results suggest there are no statistical differences in behaviour intention between the groups in all demographic factors tested towards adopting the Blockchain Technology. 
Table 3

One-way ANOVA of Demographic Profile

\begin{tabular}{|c|c|c|c|c|c|c|}
\hline Variable & & Sum of Square & df & $\begin{array}{l}\text { Mean } \\
\text { square }\end{array}$ & $F$ & Sig. \\
\hline \multirow{3}{*}{ Gender } & $\begin{array}{l}\text { Between } \\
\text { Groups }\end{array}$ & 2.208 & 1 & 2.208 & 3.573 & .062 \\
\hline & Within Groups & 60.567 & 98 & .618 & & \\
\hline & Total & 62.776 & & & & \\
\hline \multirow{3}{*}{ Age } & $\begin{array}{l}\text { Between } \\
\text { Groups }\end{array}$ & 1.264 & 3 & .421 & .658 & .580 \\
\hline & Within Groups & 61.511 & 96 & .641 & & \\
\hline & Total & 62.776 & 99 & & & \\
\hline \multirow{3}{*}{$\begin{array}{l}\text { Education } \\
\text { Level }\end{array}$} & $\begin{array}{l}\text { Between } \\
\text { Groups }\end{array}$ & .704 & 2 & .352 & .550 & .579 \\
\hline & Within Groups & 62.072 & 97 & .640 & & \\
\hline & Total & 62.776 & 99 & & & \\
\hline \multirow{3}{*}{$\begin{array}{l}\text { Position } \\
\text { Level }\end{array}$} & $\begin{array}{l}\text { Between } \\
\text { Groups }\end{array}$ & 1.318 & 2 & .659 & 1.040 & .357 \\
\hline & Within Groups & 61.458 & 97 & .634 & & \\
\hline & Total & 62.776 & 99 & & & \\
\hline \multirow{3}{*}{$\begin{array}{l}\text { Years in } \\
\text { Service }\end{array}$} & $\begin{array}{l}\text { Between } \\
\text { Groups }\end{array}$ & 3.320 & 4 & .830 & 1.326 & .266 \\
\hline & Within Groups & 59.456 & 95 & .626 & & \\
\hline & Total & 62.776 & 99 & & & \\
\hline
\end{tabular}

\subsection{Correlation and Regression Analysis}

In the next analysis, a correlation coefficient was calculated to evaluate the strength of relationship between the constructs involved in this study and Behavioural Intention (BI) towards the adoption of Blockchain technology. Table 4 displays the results from the correlation coefficient analysis. The results showed that all the constructs have a positive and significant relationship with Behavioural Intention. Performance Expectancy (PE) was found to have the highest correlation coefficient $(0.662)$ with $\mathrm{BI}$, while the correlation between $\mathrm{EE}$ and $\mathrm{BI}$ with a correlation coefficient value of 0.530 is the lowest.

Table 4

Correlation Analysis Results

\begin{tabular}{|c|c|c|c|c|c|c|c|}
\hline & & PE & $\mathrm{EE}$ & SI & FC & TR & $\mathrm{BI}$ \\
\hline \multirow{6}{*}{ rho } & PE & 1.000 & & & & & \\
\hline & $\mathrm{EE}$ & $.530^{* *}$ & 1.000 & & & & \\
\hline & SI & $.549^{* *}$ & $.674^{* *}$ & 1.000 & & & \\
\hline & FC & $.532^{* *}$ & $.790^{* *}$ & $.660^{* *}$ & 1.000 & & \\
\hline & TR & $.554^{* *}$ & $.329^{* *}$ & $.372^{* *}$ & $.447^{* *}$ & 1.000 & \\
\hline & $\mathrm{BI}$ & $.662^{* *}$ & $.440^{* *}$ & $.534^{* *}$ & $.513^{* *}$ & $.651^{* *}$ & 1.000 \\
\hline
\end{tabular}

**significant at $5 \%$ levels

In the final step, a regression analysis was conducted. In the regression model, the dependent variable is Behavioural Intention to adopt the Blockchain technology, while Performance Expectancy, Effort Expectancy, Social Influence, Facilitating Conditions, and Trust are the independent variables. Table 5 presents the results from the estimated multiple regression model. The estimation result shows that the adjusted R-square value is 0.600 indicating that about $60 \%$ of the variability in Behavioural Intention of Malaysian government officers towards Blockchain technology can be 
explained by the independent variables included in the estimation. Meanwhile, the remaining $40 \%$ are contributed by other factors that not included in the estimation. Out of five independent variables, three are statistically significant at $5 \%$ levels. The significant variables are Performance Expectancy, Social Influence, and Trust. These three variables could influence the Behavioural Intention of government officers in adopting the Blockchain Technology. Meanwhile, Effort Expectancy and Facilitating Conditions are found not statistically significant.

Table 5

Estimation Result from Regression Analysis

\begin{tabular}{lllll}
\hline Independent Variable & Coefficient & Std. Error & t-value & p-value \\
\hline Performance Expectancy & 0.359 & 0.263 & 3.894 & 0.000 \\
\hline Effort Expectancy & -0.064 & 0.091 & -0.554 & 0.581 \\
\hline Social Influence & 0.254 & 0.100 & 2.456 & 0.016 \\
\hline Facilitating Conditions & 0.014 & 0.123 & 0.115 & 0.908 \\
\hline Trust & 0.377 & 0.081 & 4.666 & 0.000 \\
\hline
\end{tabular}

Adjusted R-square 0.600

The result from regression analysis showed that variable thrust has the highest coefficient value out of three independent variables that significantly can influence the Behavioural Intention. In other words, the magnitude of the estimated coefficient suggests that trust is the most important determinant for the government officers in adopting the Blockchain technology. The finding also implied that Malaysian government officers are confident that the Blockchain technology is able to provide a safe and reliable service to the public sector. The result of this study is consistent with the finding from Groß [10] which also found that trust positively influence the use of innovative technology.

The second independent variable that statistically significant in the multiple regression model of this study is Performance Expectancy. The result infers that the expected performance of the Blockchain technology is one of the factor considered by the government officers in adopting the technology. This finding corroborates with the research finding reported by Manaf et al. [18] which found performance expectancy is positively effects supported an intention to use such technology.

The result from regression analysis found Social Influence is significantly affects the behaviour intention in adopting Blockchain technology among the government officers. The result implies that influences from the officer's close contact such as colleagues and the top management is crucial in influencing their decision to adopt the Blockchain technology. This finding, however, contradicts with Chang [4] who found a non-significant relationship between the social influence factors and behaviour intention to use a technology.

This study, however, failed to find support that Effort Expectancy (EE) and Facilitating Conditions (FC) are important factors in influencing the behavioural intention to adopt the Blockchain Technology by the Malaysian Public Sector officers. Given that Blockchain is relatively new to the Malaysian public sector, Effort Expectancy and Facilitating Conditions may not seem important due to the lack of knowledge and readiness towards the technology among the officers. Cultural and technological contexts may also affect their levels of acceptance for Blockchain technology.

\section{Conclusion}

Blockchain technology as a new technology has received lot of attention recently especially by the public sector. However, the knowledge and exposure about the technology among government officers in Malaysia are still very limited. Therefore, the purpose of this study is to investigate factors 
that may influence the behavioural intention of Malaysian public sector in adopting the Blockchain technology. There are five factors that theoretically can influence the behavioural intention were evaluated. The factors are Performance Expectancy (PE), Effort Expectancy (EE), Social Influence (SI), Facilitating Conditions (FC) and Trust (TR).

From the data that were gathered using questionnaire, this study found that most of the government officers involved in the survey are aware about the Blockchain technology. However, majority of them have inadequate exposure and knowledge about the technology. With the rapid growth in the usage of Blokchain technology globally, and for Malaysia to tap the benefits from the technology optimally, it is very crucial for the Malaysia public sector to equip their officers with the necessary knowledge about this new emerging technology. Thus, it is imperative for the government agency to allocate their resources in developing skills in the Blockchain technology.

In conclusion, government officers as policy-makers should carefully evaluate how the Blockchain technology can be applied in the public sector. Therefore, the relevant authorities should also develop a strategy to implement the suitable Blockchain application for the public sector. For this purpose, there is a need to conduct the awareness programme regarding the benefits and application of the Blockchain technology to the relevant government officers. This is because to effectively adopting the Blockchain technology is strongly depends on the sufficient understanding of the officers on how the technology works and where the application of this technology can be applied.

\section{References}

[1] Ajzen, Icek. "From intentions to actions: A theory of planned behavior." In Action control, pp. 11-39. Springer, Berlin, Heidelberg, 1985.

https://doi.org/10.1007/978-3-642-69746-3 2

[2] Ajzen, Icek. "The theory of planned behavior." Organizational behavior and human decision processes 50, no. 2 (1991): 179-211.

https://doi.org/10.1016/0749-5978(91)90020-T

[3] Akour, Hassan. Determinants of mobile learning acceptance: an empirical investigation in higher education. Oklahoma State University, 2010.

[4] Chang, Andreas. "UTAUT and UTAUT 2: A review and agenda for future research." The Winners 13, no. 2 (2012): 10-114.

https://doi.org/10.21512/tw.v13i2.656

[5] Batubara, F. Rizal, Jolien Ubacht, and Marijn Janssen. "Challenges of blockchain technology adoption for egovernment: a systematic literature review." In Proceedings of the 19th Annual International Conference on Digital Government Research: Governance in the Data Age, pp. 1-9. 2018.

https://doi.org/10.1145/3209281.3209317

[6] Davis, Fred D. "A technology acceptance model for empirically testing new end-user information systems: Theory and results." PhD diss., Massachusetts Institute of Technology, 1985.

[7] Davis, Fred D. "Perceived usefulness, perceived ease of use, and user acceptance of information technology." MIS quarterly (1989): 319-340.

https://doi.org/10.2307/249008

[8] Davis, Fred D., Richard P. Bagozzi, and Paul R. Warshaw. "User acceptance of computer technology: a comparison of two theoretical models." Management science 35, no. 8 (1989): 982-1003. https://doi.org/10.1287/mnsc.35.8.982

[9] Geroge, D., and P. Mallery. "SPSS for windows step by step: A simple guide and reference." (2003).

[10] Groß, Michael. "Exploring the acceptance of technology for mobile shopping: an empirical investigation among Smartphone users." The International Review of Retail, Distribution and Consumer Research 25, no. 3 (2015): 215 235.

https://doi.org/10.1080/09593969.2014.988280

[11] Islam, Zahidul, Patrick Kim Cheng Low, and Ikramul Hasan. "Intention to use advanced mobile phone services (AMPS)." Management Decision (2013). https://doi.org/10.1108/00251741311326590

[12] Jambulingam, Manimekalai. "Behavioural intention to adopt mobile technology among tertiary students." World applied sciences journal 22, no. 9 (2013): 1262-1271. 
[13] Kothari, Chakravanti Rajagopalachari. Research methodology: Methods and techniques. New Age International, 2004.

[14] Lee, Ji-Hwan, Soo Wook Kim, and Chi Hoon Song. "The effects of trust and perceived risk on users' acceptance of ICT services." (2010). https://doi.org/10.2139/ssrn.1703213

[15] Leong, Lai-Ying, Teck-Soon Hew, Garry Wei-Han Tan, and Keng-Boon Ooi. "Predicting the determinants of the NFCenabled mobile credit card acceptance: A neural networks approach." Expert Systems with Applications 40, no. 14 (2013): 5604-5620. https://doi.org/10.1016/i.eswa.2013.04.018

[16] Lewis, Carmen C., Cherie E. Fretwell, Jim Ryan, and James B. Parham. "Faculty use of established and emerging technologies in higher education: A unified theory of acceptance and use of technology perspective." International Journal of Higher Education 2, no. 2 (2013): 22-34. https://doi.org/10.5430/ijhe.v2n2p22

[17] Mafé, Carla Ruiz, Silvia Sanz Blas, and Juan Fernando Tavera-Mesías. "A comparative study of mobile messaging services acceptance to participate in television programmes." Journal of service Management (2010).

[18] Manaf, N. R., and Maya Ariyanti. "Exploring Key Factors on Technology Acceptance of Mobile Payment Users in Indonesia Using Modified UTAUT2 Model Use Case: ABC Easy Tap." International Journal of Management and Applied Science 3, no. 1 (2017): 40-44.

[19] Mayer, Roger C., James H. Davis, and F. David Schoorman. "An integrative model of organizational trust." Academy of management review 20, no. 3 (1995): 709-734. https://doi.org/10.5465/amr.1995.9508080335

[20] MIMOS Berhad. (2017). Blockchain: 5 things we know so far. Retrieved April 4, 2018, from http://www.mimos.my/paper/blockchain-5- things-we-know-so-far/.

[21] Marten, Risius, and Spohrer Kai. "A blockchain research framework-What we (don't) know, where we go from here, and how we will get there." Business \& information systems engineering 59, no. 6 (2017): 385-409. https://doi.org/10.1007/s12599-017-0506-0

[22] Rogers, E. M. "(1995). Diffusion of innovations. New York: Free Press." (1962).

[23] Sekaran, Uma, and Roger Bougie. Research methods for business: A skill building approach. John Wiley \& Sons, 2016.

[24] Sun, Quan, Hao Cao, and Jianxin You. "Factors influencing the adoption of mobile service in China: An integration of TAM." JCP 5, no. 5 (2010): 799-806. https://doi.org/10.4304/jcp.5.5.799-806

[25] Tan, Garry Wei-Han, Keng-Boon Ooi, Jia-Jia Sim, and Kongkiti Phusavat. "Determinants of mobile learning adoption: An empirical analysis." Journal of Computer Information Systems 52, no. 3 (2012): 82-91.

[26] Tavakol, Mohsen, and Reg Dennick. "Making sense of Cronbach's alpha." International journal of medical education 2 (2011): 53. https://doi.org/10.5116/ijme.4dfb.8dfd

[27] Venkatesh, Viswanath, Michael G. Morris, Gordon B. Davis, and Fred D. Davis. "User acceptance of information technology: Toward a unified view." MIS quarterly (2003): 425-478. https://doi.org/10.2307/30036540

[28] Venkatesh, Viswanath, James YL Thong, and Xin Xu. "Consumer acceptance and use of information technology: extending the unified theory of acceptance and use of technology." MIS quarterly (2012): 157-178. https://doi.org/10.2307/41410412

[29] Wu, Yu-Lung, Yu-Hui Tao, and Pei-Chi Yang. "Using UTAUT to explore the behavior of $3 G$ mobile communication users." In 2007 IEEE international conference on industrial engineering and engineering management, pp. 199-203. IEEE, 2007. https://doi.org/10.1109/IEEM.2007.4419179

[30] Foon, Yeoh Sok, and Benjamin Chan Yin Fah. "Internet banking adoption in Kuala Lumpur: an application of UTAUT model." International Journal of Business and Management 6, no. 4 (2011): 161. https://doi.org/10.5539/ijbm.v6n4p161 